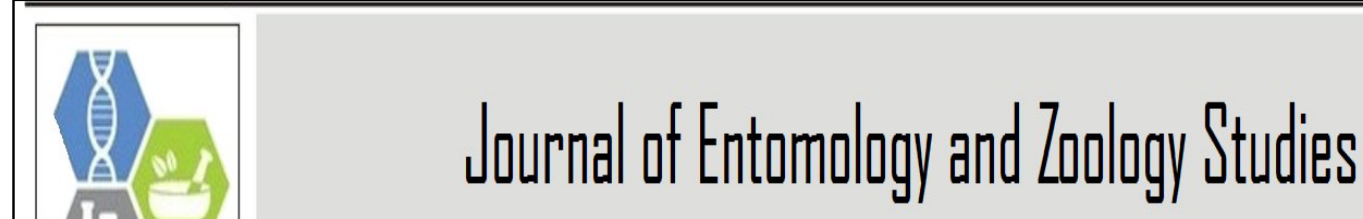

Available online at www.entomoljournal.com

E-ISSN: 2320-7078 P-ISSN: 2349-6800 JEZS 2016; 4(6): 804-805

(C) 2016 JEZS

Received: 18-09-2016

Accepted: 19-10-2016

Mark Ian Cooper

Department of Biological

Sciences, University of Cape

Town, Rondebosch 7701

South Africa
Correspondence

Mark Ian Cooper

Department of Biological

Sciences, University of Cape

Town, Rondebosch 7701,

South Africa

\section{The influence of male body mass on copulation duration in Centrobolus inscriptus (Attems)}

\section{Mark Ian Cooper}

\section{Abstract}

Body size is a known correlate of copulation duration in some animals. Here I test for the presence of a relationship between male body mass and copulation duration in Centrobolus inscriptus by performing mating experiments. Males differed significantly from females in body mass, body length, and dorsal tergite width. Copulation durations of second males were significantly related to their body mass (Figure 1: $\mathrm{R}^{2}=0.68$, d. f. $=7, \mathrm{p}=0.01$ ). Males which mate last prolong copulations in accordance with their body size, which may assure paternity.

Keywords: Arthropods, body size, Centrobolus, copulation duration

\section{Introduction}

Male and female body sizes can influence the duration of copulation in arthropods $e . g$. Drosophila melanogaster ${ }^{[1]}$. Body size and morph are known drivers of copulation duration ${ }^{[2]}$. These factors may be interdependent ${ }^{[3]}$. The interdependence of male and female body size on each other is manifest in the relationship between reversed sexual size dimorphism (SSD) and copulation duration ${ }^{[4]}$. Here I test for the presence of a relationship between male body mass and copulation duration in the millipede Centrobolus inscriptus. The null hypothesis is there is no relationship between male body mass and copulation duration in any of the matings.

\section{Materials and methods}

Millipedes were collected in April 1995 from Zululand (Twin streams farm, Mtunzini). Live specimens of each sex were transported to the laboratory where conditions were kept under a constant regime of $25^{\circ} \mathrm{C}$ temperature; 70\% relative humidity; 12: 12 hrs light-dark cycle. Food was provided in the form of fresh vegetables ad libitum. Individuals had unknown mating histories. Unisex groups were housed in plastic containers containing moist vermiculite ( $\pm 5 \mathrm{~cm}$ deep) for 10 days before commencing the first mating experiments. Three measurements were taken for all individuals once copula pairs had disengaged; body mass (accurate to $0.01 \mathrm{~g})$, body length $(\mathrm{mm})$, and dorsal tergite width $(\mathrm{mm})$. Animals were placed into glass mating arenas $(30 \times 22 \times 22 \mathrm{~mm})$. Individuals were marked on the posterior segments with coloured tipex fluid (perfect A16) prior to mating. This allowed data from each individual to be integrated. Single, double, and artificially-terminated mating with females were allowed. Approximately five minutes after establishing a pairs were removed from the mating arena and placed into plastic beakers $(13 \mathrm{~cm}$ diameter). This prevented interference from other males and allowed easy timing of the copulation durations. Statistical analyses were performed using Statgraphics (version 6.0). Morphometric data were tested for normality before comparing males and females using a Student's t-test. The ability of body mass to explain body length and dorsal tergite width was determined using linear regression analysis.

\section{Results}

Males differed significantly from females in body mass (students t-test: $t=9.38$, d. $f$. $=95$, $p<0.05)$, body length $(\mathrm{t}=-2.19, \mathrm{~d} . \mathrm{f} .=95, p<0.005)$, and dorsal tergite width $(\mathrm{t}=24.21$, d. f. $=$ $95, p<0.005)$. Copulation durations of second males were significantly related to their body masses (Figure 1: $\mathrm{R}^{2}=0.68$, d. f. $=7, \mathrm{p}=0.01$ ). Similar relationships, between all combinations of copulation duration and male and female body masses, were absent from other double mating $\left(\mathrm{R}^{2}<0.42\right.$, d. f. $\left.=6, p>0.05\right)$. 


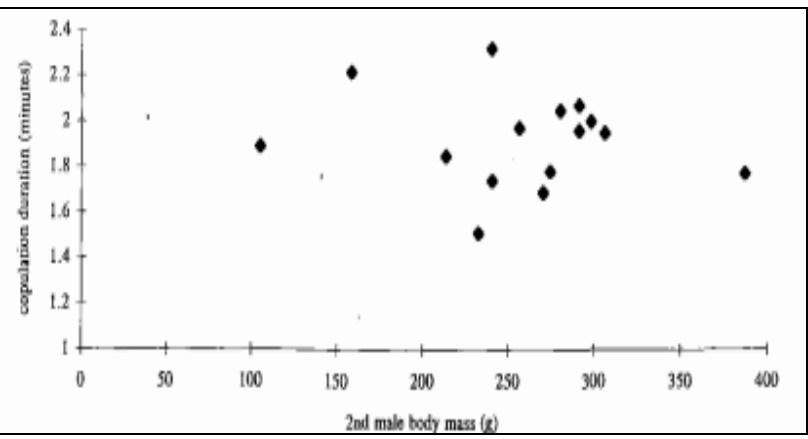

Fig 1: The relationship between copulation duration and body mass of males mating last in the double mating of Centrobolus inscriptus (Attems).

\section{Discussion}

Copulations of second males were significantly related to male body mass in the presence of sexual size dimorphism (Figure 1). In C. inscriptus the ratio of body length: width falls beyond the $7-9.5$ range given for other Centrobolus ${ }^{[4-5]}$. The ratio differs little between the sexes, suggesting that there may be increased insemination efficiency via close apposition of male and female genitalia ${ }^{[6]}$. This would result in sizeassortative mating, which was found in C. inscriptus [4]. Morphometric trends do however suggest that males may be adapted for increased mobility and ability to locate females ${ }^{[7]}$. In males the bodies are more streamlined and possess longer legs ${ }^{[8]}$. When engaging in mate-searching behaviour, large amounts of time may have to be diverted from foraging to reproduction behaviours ${ }^{[9]}$. The serious energetic constraints imposed on males is significant in species with prolonged breeding periods. The prolonged copulation durations in $C$. inscriptus may place selection pressures on male body size. Males that mate last prolong copulations in accordance with their body size, which may assure paternity.

\section{Conclusion}

Copulations of second males were significantly related to male body mass in the presence of sexual size dimorphism in double mating experiments of $C$. inscriptus.

\section{References}

1. Lefranc A, Bungaard J. The influence of male and female body size on copulation duration and fecundity in Drosophila melanogaster. Hereditas. 2000; 132:243-247. DOI: $10.1111 / \mathrm{j} .1601-5223.2000 .00243 . x$.

2. Wong-Muñoz J, Anderson $\mathrm{CN}$, Munguía-Steyer $\mathrm{R}$, Córdoba-Aguilar A. Body Size and Morph as Drivers of Copulation Duration in a Male Dimorphic Damselfly. Ethology. 2013; 119(5):407-416.

DOI: 10.1111/eth.12077.

3. Walzer A, Schausberger P. Interdependent effects of male and female body size plasticity on mating behaviour of predatory mites. Animal Behaviour. 2015; 100:96-105. http://dx.doi.org/10.1016/j.anbehav.2014.11.017.

4. Cooper MI. Sexual conflicts over duration of copulation in Centrobolus inscriptus (Attems). Journal of Entomology and Zoology Studies. 2016; 4(6):. DOI: 10.13140/RG.2.2.31736.24325.

5. Lawrence RF. The centipedes and millipedes of southern Africa: A guide. Cape Town \& Rotterdam: A.A. Balkema. 1983.

ISBN 10: 0869611429 ISBN 13: 9780869611425.

6. Licht LE. Sexual selection in toads (Bufo americunus).
Canadian Journal of Zoology. 1976; 54(8):1277-1284. DOI: $10.1139 / \mathrm{z} 76-145$.

7. Ghiselin MT. A Radical Solution to the Species Problem. Systematic Zoology. 1974; 23(4):536-544. DOI: 10.1093/sysbio/23.4.536.

8. Cooper MI. The relative sexual size dimorphism of Centrobolus inscriptus (Attems) compared to 18 congenerics. Journal of Entomology and Zoology Studies. 2016; 4(6):504-505.

DOI: 10.13140/RG.2.2.25025.35680

9. Woolbright LL. Anuran Size Dimorphism: Reply to Sullivan. The American Naturalist. 1985; 125(5):741743. DOI: $10.1086 / 284376$ 